\title{
Still seeking for an explanation of the Sequential Compatibility Effect
}

\author{
Jesús Privado ${ }^{1 *}$, Juan Botella ${ }^{2}$, Manuel Suero ${ }^{2}$, María Ángeles Quiroga ${ }^{1}$ and Roberto Colom ${ }^{2}$ \\ 1 Universidad Complutense de Madrid \\ 2 Universidad Autónoma de Madrid
}

\begin{abstract}
Título: En busca de una explicación del Efecto Secuencial de Compatibilidad. Resumen: Se estudia la modulación del Efecto de Compatibilidad (EC) según la compatibilidad del ensayo previo (Efecto Secuencial de Compatibilidad, ESC) en tres tipos de tareas atencionales, flancos verbal, flancos numérico y Stroop espacial, modeladas a partir de Gratton et al., (1992). Las tareas de flancos y Stroop espacial presentan diferente complejidad cognitiva. Se analiza en estas tareas si la modulación del EC está matizada por la repetición de estímulos exactamente iguales consecutivos (puras réplicas) o es independiente de ésta. Se registran datos de tres muestras independientes $\left(N_{\text {total }}\right.$ $=1.159$ ) para averiguar si los resultados logran reproducirse. Se observa EC para las tres tareas atencionales, pero sólo hay ESC en la tarea de Stroop espacial. El efecto se mantiene después de eliminar del análisis los ensayos que son puras réplicas, un resultado inconsistente con las propuestas de Mayr et al. (2003) y Hommel (1998) pero congruente con la Teoría del Conflicto (Botvinick et al., 2001). Además, se analiza la importancia de la complejidad cognitiva en relación a la perspectiva de Botvinick et al. (2004) Desde este punto de vista una mayor complejidad se debería reflejar en una mayor presencia de conflicto cognitivo, y, por tanto, un mayor ESC.

Palabras claves: Control atencional; conflicto cognitivo; efecto de compatibilidad; efecto secuencial de compatibilidad.
\end{abstract}

\section{Introduction}

\section{Cognitive Control}

Baddeley (2002) defined Attentional Control as the ability to focalize attention, a feature of the central executive. Engle, Kane and Tuholski (1999) consider it as an ability to maintain active mental representations when there is interference or cognitive conflict. Botvinick, Braver, Barch, Carter, and Cohen (2001) describe the cognitive control as a cognitive system ability that helps to configure itself in order to achieve better results in especially changing situations in which there is conflict or competition between different stimuli. Therefore, cognitive control is considered by many authors as a top-down process that regulates external information.

It is a common result in speeded experimental tasks that it takes less time responding to trials in which only the relevant stimuli are presented (to be answered) than trials in which the relevant stimuli are accompanied with irrelevant stimuli (not to be answered). The presence of irrelevant stimuli produces cognitive conflict in the second kind of trials. The cognitive system fails in processing information selectively, i.e., it is unable to ignore not attending irrelevant stimuli (Botella, 1997, 1998). But there are individual differences. Those with better performance on tasks that tax in Attentional Control have greater ability for cognitive control

* Dirección para correspondencia [Correspondence address]: Jesús Privado. Universidad Complutense de Madrid. Facultad de Psicología. Departamento de Metodología de las Ciencias del Comportamiento, Campus de Somosaguas, 28223, Pozuelo de Alarcón, Madrid (Spain). Email: jesus.privado@pdi.ucm.es

\begin{abstract}
The modulation of the Compatibility Effect (CE) according to the compatibility of the previous trial (Sequential Compatibility Effect, SCE) in three types of attentional tasks is explored. The flankers and spatial Stroop tasks have different degrees of cognitive complexity. In all three tasks it is analyzed whether the SCE varies when the stimuli in consecutive trials are exactly the same (pure replicas) or not. The data, collected from three independent samples (total $N=1.159$ ), show the $\mathrm{CE}$ in the three tasks. However, SCE only shows up in the spatial Stroop task. The effect is smaller albeit still significant when the pure replica trials are removed, a result inconsistent with those of Mayr et al. (2003) and Hommel (1998) but consistent with the Conflict Theory (Botvinick et al., 2001). Furthermore, we also discuss the importance of cognitive complexity in relation to the perspective of Botvinick et al. (2004). From this point of view more complexity should be reflected in a greater presence of cognitive conflict, and therefore a higher SCE.

Key words: Attentional control; cognitive conflict; compatibility effect; se-
\end{abstract} quential compatibility effect. over the stimuli. Therefore, they attenuate more the processing of irrelevant stimuli or at least they achieve that its processing does not interfere with the processing of the relevant stimuli.

Tasks measuring Attentional Control usually show some conflict between the stimuli relevant to the task and the irrelevant stimuli. Some examples are the Stroop task, the Simon effect and the flankers task. Considering the difference between the mean reaction time (RT) of relevant and irrelevant trials and their order of presentation, we can define two types of measures of cognitive conflict: Compatibility Effect and Sequential Compatibility Effect (Gratton, Coles, \& Donchin, 1992).

\section{Compatibility Effect (CE)}

The flankers paradigm was developed by Eriksen and Eriksen (1974) to study the ability to select relevant information in a spatial localization task. Its most common form presents two types of items: (a) one is the target and is located at the center of the display, and (b) other (flankers) are displayed at both sides of the target; they should be ignored. In the condition of compatible flankers, the target and the flankers have the same identity, and therefore have the same response associated. In the condition of incompatible flankers, both have different identity and different response associated. Finally, in the condition of neutral flankers both have different identity and the flankers have no response associated. For example, if the letters used are H-S-V and the task is to press a key when the middle letter is $\mathrm{S}$ and press another key different when the middle letter is $\mathrm{H}$, there are six types of presentations: HHHHH, SSSSS, HHSHH, SSHSS, 
VVHVV and VVSVV. The first two trials are compatible, the next two are incompatible and the last two are neutral.

The main result with this task is that the mean $\mathrm{RT}$ in the compatible condition is shorter than in the other two conditions, while the mean RT in the incompatible condition is larger than in the others two; this is known as the Compatibility Effect (CE). In this study, the CE is operationally defined as the difference between the mean RT in the incompatible $\left(\mathrm{RT}_{\mathrm{I}}\right)$ and compatible $\left(\mathrm{RT}_{\mathrm{C}}\right)$ conditions:

$$
\mathrm{CE}=\mathrm{R} T_{I}-\mathrm{R} T_{C}
$$

According to the zoom-lens model for spatial selective attention, we have the ability to adjust the size of the attentional focus according to the task goals (Barriopedro \& Botella, 1998; Erkisen \& St. James, 1986; Eriksen \& Yeh, 1985). However, the flankers effect reflect a limitation in such ability, in the same vein as many other functions of the selective attention show limitations.

For the Simon task (Simon \& Rudell, 1967) it is manipulated the correspondence between the position of the stimulus and the response position. For example, the target could be a letter (A or B) that can appear to the left or right of the center of the screen. The task is pressing as fast as possible the left button when the letter $\mathrm{A}$ is presented, and the right button when the letter B is presented, regardless of at which side of the fixation point the letter appears. The usual result is that the mean RT is smaller when the spatial location of the stimulus and the response position match, i.e., when the letter $\mathrm{A}$ is presented at the left of the fixation point (compatible trial) the RT is smaller than when it appears at the right of the fixation point (incompatible trial). Therefore, what is produced is a CE based on the stimulus-response spatial correspondence.

\section{Sequential Compatibility Effect}

The Sequential Effect (Bertelson, 1961) refers to the fact that the RT in a serial choice task is not independent of what happened in the previous trials. The response to a stimulus is different when the same stimulus is repeated on consecutive trials than when it changes. Soetens, Boer and Hueting (1985) found that the RT decreases when the same stimulus is repeated in several consecutive trials, and increase when the stimuli alternate.

Two independent mechanisms have been proposed to explain the sequential effects in a choice task with two alternatives: automatic facilitation and subjective expectancy. The automatic facilitation mechanism predicts that exactly equal stimuli (pure replicas) must increase performance (smaller RT) as compared with alternating sequences. The subjective expectation mechanism assumes that some hypothesis is set by the observer before the stimulus is presented. The empirical result, repeatedly observed, is that with short intervals between stimuli $(\approx 100 \mathrm{~ms}$ ) repetitions are facilitators, and the results are explained by automatic facilitation. However, when the interval is long repetitions increase the RT, and the subjective expectation is the mechanism that accounts the results. This matches with the view that the expectation is a topdown process, controlled by the cognitive system, so it needs more time. By contrast, the facilitation is a bottom-up process, controlled by the stimuli, requiring less time to observe its effects (e.g., Soetens, 1998; Soetens \& Notebaert, 2005).

Gratton et al. (1992) were pioneers in studying the sequential effects using the paradigm of flankers of Eriksen and Eriksen (1974). As Soetens (1985), they employed a two alternative choice task to study sequential effects. However, in each trial the target was flanked by distracter stimuli, irrelevant for the task, but that could be compatible, incompatible, or neutral, in the sense of the Eriksens' paradigm. The main novelty of Gratton et al. (1992) is that they studied how the CE changes as a function of the condition of compatibility in the previous trial. That is, the effects of repetition or alternation of the condition of compatibility in consecutive trials ( $\mathrm{N}$ and $\mathrm{N}-1)$ in a flankers task of letters. Four types of sequences must be distinguished: compatible trial preceded by a compatible trial $(c C)$, compatible trial preceded by an incompatible trial $(i C)$, incompatible trial preceded by another incompatible trial (iI) and incompatible trial preceded by a compatible trial $(c I)$. Stimuli were displayed for $100 \mathrm{~ms}$ with an inter-stimulus interval between 3500 and $5500 \mathrm{~ms}$. Their results agree with what is usually observed: the RT is shorter in compatible than in incompatible trials (the $\mathrm{CE}$ ). Their main result was that the $\mathrm{CE}$ was modulated by the condition of compatibility of the previous trial. Specifically, the CE was smaller when the previous trial was incompatible as compared with trials preceded by compatible trials, a phenomenon that has been labeled Sequential Compatibility Effect (SCE).

The procedure for estimating the size of the SCE is as follows:

$$
\mathrm{SCE}=\left(R T_{c I}-\mathrm{R} T_{c} \mathrm{C}\right)-\left(\mathrm{R} T_{i I}-\mathrm{R} T_{i C}\right)
$$

Gratton et al. (1992) argue that these results cannot be explained by the facilitation caused by repetition of the previous trial on the current trial, but by the repetition of the compatibility condition. The expectation created by the type of compatibility of previous trial influences on the response given in the current trial.

Botvinick et al. (2001) and Botvinick, Cohen and Carter (2004) try to explain the results of Gratton et al. (1992) through the concept of Cognitive Control. They wonder how it is managed the conflict that occurs in tasks in which stimuli are associated with two different types of responses, as in the flankers and Simon tasks.

Botvinick et al. (2001) proposed the Conflict Monitoring Theory according to which there is a system that monitors the presence of conflict compensating the system to reduce the impact of conflict as follows: first, the system evaluates the levels of conflict, then transfers the information to the cen- 
ters of cognitive control and, finally, set the system to try to prevent or reduce conflict. The activation of competitive responses (in incompatible or incongruent conditions) increase the top-down control of the cognitive system on the information processing. Botvinick et al. (2001) propose a computational model of neural networks to explain the conflict monitoring in a wide range of behavioral contexts. The main feature of this model, as compared to other similar models (Cohen \& Huston, 1994; Cohen, Servan-Schreiber \& McClelland, 1992; McClelland \& Rumelhart, 1981), is the conflict monitoring unit responsible for reducing or managing cognitive conflict. The explanation for the SCE is as follows: incompatible trials produce more cognitive activation than compatible ones, since in the incompatible trials there is more conflict. The increased level of control is still active when the stimuli of the following trial are presented. Thus, the RT in iI is shorter as compared to when the sequence is compatible followed by incompatible $(c I)$, because compatible trials require less activation and, therefore, the following trial begins with a lower level of activation.

One of the features of the theory of Botvinick et al. (2001) is that they have been seeking for neural correlates of the presence of conflict in experimental tasks. They argue that activation of anterior cingulate cortex (ACC) can be considered a reaction to the occurrence of conflict and is expected to be greater the longer the conflict. Egner and Hirsch (2005), MacDonald III, Cohen, Stenger and Carter (2000) and Kerns et al. (2004) observed increased activation of the ACC in trials with greater conflict (incompatible) in a Stroop task; Van Veen, Cohen, Botvinick, Stenger and Carter (2001) found increased activation in the ACC in the presence of incompatible trials in a flankers task. However, they also found contrary results, observing a lack of relationship between ACC and the presence of conflict in flankers tasks (Casey et al., 2000), Stroop tasks (Milham \& Banich, 2005) and Simon tasks (Burle, Allain, Vidal \& Hasbroucq, 2005).

In their review of the Conflict Monitoring Theory Botvinick et al. (2004) suggest that conflict can be an index of cognitive demands to make a mental effort, as there is evidence that the ACC is more active in cognitively loaded tasks. Moreover, they argue that the conflict can occur at different levels of information processing, from perceptual representation to the categorization of stimuli, through the selection of information and representation.

Mayr, Awh and Laurey (2003) suggest that the SCE can be explained by Perceptual Priming and, therefore, the processing would not be top-down, guided by the cognitive system, but bottom-up, guided by the stimulus. The repetition of the same stimulus in consecutive trials may explain the lower RT in incompatible trials preceded by another incompatible (iI) when the interval between the stimuli is short $(1000 \mathrm{~ms})$. In this study, when the analysis eliminates consecutive trials with exactly the same stimuli (pure replicas) of a spatial flankers task, the SCE disappears. Examples of pure replicas would be: $\mathrm{N}-1(<<<)$ and $\mathrm{N}$
$(<<<), \mathrm{N}-1 \quad(><>)$ and $\mathrm{N}(><>)$; and trials in which the condition of compatibility is repeated but the stimuli are not exact replicas are, for example: $\mathrm{N}-1(<<<)$ and $\mathrm{N}(>>>)$, $\mathrm{N}-1(><>)$ and $\mathrm{N}(<><)$. Notice that pure replicas trials only are possible in the sequences $c C$ and iI. However, Ullsperger, Bylsma and Botvinick (2005) performed two experiments: in one of them eliminated repeated stimuli in a spatial flankers task, and in the other designed numerical flankers in which there is no pair of repeated stimuli; SCE is found in both experiments, although it should be highlighted that the interval between the stimuli is superior to that employed by Mayr et al. (2003), since it is between $5000-6000 \mathrm{~ms}$ for the spatial task and between 3500-5000 $\mathrm{ms}$ for the numerical task. Another difference between the study of Mayr et al. (2003) and Ullsperger et al. (2005) is that in the study of Mayr et al (2003) the stimulus remains on the screen until the response, while in that of Ullsperger et al (2005) the stimulus disappears after 100-377 ms. That is, Mayr et al. (2003) employed tasks that facilitate priming between stimuli, holding the stimulus the maximum time on the screen.

Some authors, using shorter intervals between stimuli as those employed by Mayr et al. (2003) found SCE, while others do not. On one hand, Notebaert, Gevers, Verbruggen and Liefooghe (2006) studied the SCE in a Stroop task with different intervals between 50 and $200 \mathrm{~ms}$ stimuli and leaving the stimulus on the screen until a response was given. They found this effect clearly, both when all trials were included in the analysis and when the pure replicas were removed. Moreover, the CE disappeared completely when the previous trial was incompatible and the interval was $50 \mathrm{~ms}$. Also, Notebaert and Verguts (2007) analyzed the results of a flankers task with an interval of $800 \mathrm{~ms}$ between stimuli and found that trials in which there was no repetition contributed significantly to explain the presence of cognitive conflict in the task, which contradicts the viewpoint of Mayr et al. (2003). Furthermore, Nieuwenhuis et al. (2006) used tasks of arrows as flankers with a stimulus interval of $1.000 \mathrm{~ms}$ and with the following variations. First, presenting the flankers $100 \mathrm{~ms}$ before the target and then keeping them near the target on the screen until a response is given, so that there were greater conflict between the flankers and the target. Second, emphasizing in the instructions the speed in the response; they should make the response as quickly as possible, even although mistakes are committed (another way to increase the conflict), and providing trial-totrial feedback of the responses. Furthermore, in order to assess the degree of generalization at different ages, they applied a flankers task of arrows where the stimulus was presented for $800 \mathrm{~ms}$ and with an interval of $2500 \mathrm{~ms}$ between stimuli to a group of 892 participants of 12,25 and 50 years old. Despite all these changes, they obtained the same results in the flankers task that Mayr et al. (2003), i.e., the SCE disappears when pure replicas are removed from the analysis.

Hommel and his colleagues (1998, 2004, 2007), in their Feature Integration Theory, presents an approach consistent 
with that of Mayr et al. (2003) that explains the SCE as a priming effect. Hommel argues that if a response and a stimulus co-occur in time their characteristics get associated or integrated. Therefore, the activation of one member of the association tends to activate the other member, resulting in a benefit or stimulus-response priming. That is, if the stimulus is presented to the left of the screen as in a Simon task, and the correct answer in this case is pressing a key on the left of the keyboard (or with the left hand), the RT will be smaller due to the association between the position of the stimulus and the associated response. However, if the stimulus is presented to the left and the correct answer is to press a button on the right, the presence of the stimulus to the left automatically activate the response of the left, so it will increase the RT. Simon task using intervals between stimuli of 1000 $\mathrm{ms}$ and manipulating the presentation time on the screen of stimuli with values of 400 and 1500, Hommel, Proctor and $\mathrm{Vu}$ (2004) found CE in the trial $\mathrm{N}$ when the trial N-1 was compatible, but not when it was incompatible. Therefore, they found SCE. However, when examining the effects of repeated stimulus-response localization discovered that the CE would disappear if there was alternating trials of the stimulus-response location, so that the results can be explained in terms of Feature Integration Theory. These results were similar to the results of Wendt, Kluwe and Peters (2006). Conversely, Wühr and Ansorge (2005) applied a Simon task presenting the stimuli during $250 \mathrm{~ms}$. Manipulating the interval between stimuli with values of 1500, 2600 and $6000 \mathrm{~ms}$ obtained SCE in all three cases, although this decreases as the interval is increased and, moreover, the SCE was unaffected by repetition or alternation stimulusresponse, a result that contradicts the predictions of Hommel (1998, 2004, 2007).

In summary, there are three main theoretical approaches to the sequential effects observed in experimental tasks of response competition (cognitive conflict): Conflict Monitoring Theory (Botvinick et al., 2001, 2004), Perceptual Priming (Mayr et al., 2003) and Feature Integration Theory (Hommel, 1998, 2004). Botvinick links the SCE to the presence of cognitive conflict between relevant and irrelevant stimuli. The other two interpreted the SCE either as an effect of repeated trials with exactly the same stimuli, arguing that it is a methodological artifact rather than a relevant empirical evidence (Mayr et al, 2003), or as the result of a spatial stimulusresponse correspondence and representations of stimulusresponse features (Hommel, 1998).

\section{The aim}

Our main objective is to analyze the effect of the modulation of $\mathrm{CE}$ according to the compatibility of the previous trial of a sequence of trials on three attentional tasks of cognitive conflict: two flankers tasks (verbal and numerical) and a spatial Stroop. Flankers tasks have higher cognitive complexity than spatial. Cognitive complexity is an important dimension to explain how they are approached by the partic- ipants (Arend, Colom, Botella, Contreras, Rubio \& Santacreu, 2003). While in the flankers tasks the association between stimuli (numbers or letters) and the response is arbitrary, which requires the subject to process this association in a controlled manner, in the spatial Stroop task the location of the stimuli (left or right) and of the two response keys (press with left or right hand) is not arbitrary, involving more automatic processing. Therefore, in the flankers tasks there is an operation that is not present in the spatial Stroop task, which makes the last one less complex.

We also examine whether the SCE is modulated by exact repetitions of the same stimuli (pure replicas). That is, we examine whether these three tasks show the SCE found by Gratton et al. (1992) and will be compared with predictions from the three models. The attentional tasks were applied to three independent samples composed of a total of 1,159 participants.

\section{Method}

\section{Participants}

Participants were recruited from three consecutive cohorts of students of size 379,358 and 422, with mean age of 20.28 years $(S D=2.70), 20.35$ years $(S D=3.17)$, and 20.35 years $(S D=3.17)$, respectively. The total sample comprised approximately $80 \%$ of females, uniformly distributed in the three samples.

\section{Apparatus and stimuli}

Stimuli were presented on a monitor connected to a PC. The experiment was programmed in Visual Basic 6.0 by the first author (J.P.). Stimuli subtended $0.64^{\circ}$ high and $0.29^{\circ}$ wide, presented at $50 \mathrm{~cm}$ distance. The font used for the stimuli was Courier New Bold size 20. The color of the stimuli was black $[\operatorname{RGB}(0,0,0)]$, while the background was cyan [RGB (150, 200, 250)].

The Spatial Stroop task consisted of the presentation of an arrow, at the left or right of a central cross (fixation point), that could point to the left or right. Specifically, there could be four types of trials: $<+,+>,>+,+<$. The participant had to press a key quickly with the left hand if the arrow was pointing to the left and another key with the right hand if it was oriented to the right, regardless of the side of the central cross where the arrow appeared. Therefore, the first two types of trials were compatible and the last two trials were incompatible.

The Numerical Flankers task consisted of three digits presented in the center of the screen. The central digit could be the same or different than the digit at the sides. Digits 1 to 9 were used as stimuli. There are four types of trials, according to the category (odd or even) of the target and the flankers: EEE, OOO, EOE, OEO. The compatible trials were always of identical type. That is, when the target and the flankers were both odd or even, they were the same 
digit. The task was to press a key as fast as possible with one hand when the central digit was odd and with the other hand when it was even.

The Verbal Flankers task consisted of three letters presented in the center of the screen. The center letter could be the same or different than those at the sides. The stimuli used were the five vowels and the following five consonants: G, K, S, P, X. All were presented in uppercase. The four types of trials in this task, according to the category of the letter, were: VVV, CCC, VCV, CVC. As in the previous task compatible trials were always of identical type. The participant's task was to press a key quickly with one hand when the central letter was a vowel and with the other hand when it was a consonant.

Note that while in the flankers tasks the association between the stimulus and the response is arbitrary, which require controlled processing, in the Stroop spatial task the association between stimuli and responses involves a more automatic processing. Thus we can consider flankers tasks as cognitively more complex than the spatial Strrop task.

\section{Procedure}

The procedure in the three types of tasks was identical except for the type of stimulus presented in each case (see Figure 1). Participants were placed at about $50 \mathrm{~cm}$ from the screen. Each trial began with the fixation point (a cross) for $1000 \mathrm{~ms}$, in the center of the screen. Then the stimuli were displayed and remained on the screen until the participants' response by pressing the 1 or 0 on the keyboard; then, the screen remained empty for $1000 \mathrm{~ms}$. Therefore, the interval between stimulus (from the moment when the stimuli of a trial disappeared until the stimuli of the next trial appeared) was $2000 \mathrm{~ms}$. The total duration of a trial was variable, as it depended of the response time in the trial. The experimental condition and the specific stimuli for each trial were randomly determined for each participant just before the beginning of the trial.

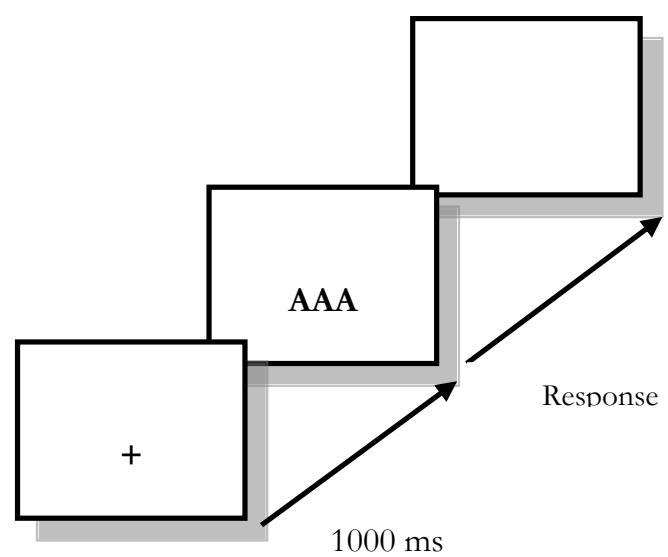

1000 $\mathrm{ms}$

Figure 1. Schematic sequence of the procedure for the three experimental tasks.
All participants performed, for each task, a practice block of 20 trials and an experimental block of 80 trials (40 compatible and 40 incompatible trials). The total time spent performing the three tasks was about 20 minutes in a single session. All tasks were administered to all participants (see an exception below). For all trials of each condition the trimmed average RT was calculated: RT $\leq 200 \leq 2000 \mathrm{~ms}$, using only the trials with a correct response. Trimmed average is used to eliminate trials that are probably anticipations $(<200 \mathrm{~ms})$ and trials in which the participant was probably distracted ( $>2000 \mathrm{~ms})$.

\section{Design}

The experimental design was within-subjects, since all participants performed all experimental conditions. In the case of the first sample they were applied only the Numerical Flankers task and the spatial Stroop. The letters task was only employed with the other two samples. The order of application of the tasks was the same for all participants: first, the Verbal Flankers, then the Numerical Flankers, and finally the spatial Stroop.

\section{Results}

In order to explore whether the SCE is due to priming produced by the previous trial $(\mathrm{N}-1)$ in the current trial $(\mathrm{N})$, there were two types of analysis: including all trials and eliminating those that were pure replicas. We conducted repeated measures ANOVAs 2x2 for mean RT of the four types of trials depending of two factors: the compatibility of the present trial, $\mathrm{N}$ (compatible or incompatible) and the compatibility of the previous trial, N-1 (compatible or incompatible). These four values appear in formula (2) which reflects the magnitude of the SCE: $\mathrm{RT}_{\mathrm{cI}}, \mathrm{RT}_{\mathrm{cC}}, \mathrm{RT}_{\mathrm{iI}}, \mathrm{RT}_{\mathrm{iC}}$. In that formula $\mathrm{RT}_{\mathrm{CI}}$ is the average $\mathrm{RT}$ of the incompatible trials preceded by a compatible trial and $\mathrm{RT}_{\mathrm{iI}}$ is the mean of incompatible trials preceded by an incompatible trial $\left(\mathrm{RT}_{\mathrm{cC}}\right.$ and $\mathrm{RT}_{\mathrm{iC}}$ follow the same logic).

\section{Spatial Stroop}

The results of the ANOVA indicate that the main factor, trial $\mathrm{N}$ compatibility, is statistically significant when all trials are included in the analysis, for the first sample $[F(1,377)=$ 553.21, $p<.001$, partial $\left.\eta^{2}=.595\right]$, the second sample $\left[F(1,477)=1,008.08, p<.001\right.$, partial $\left.\eta^{2}=.679\right]$ and the third sample $\left[F(1,416)=708.03, p<.001\right.$, partial $\left.\eta^{2}=.630\right]$. When pure replicas are eliminated, the results are also statistically significant in all cases: first sample, $F(1,377)=441.29$, $p<.001$, partial $\eta^{2}=.539$ ]; second sample, $F(1,476)=$ $739.54, p<.001$, partial $\eta^{2}=.608$; third sample, $F(1,416)=$ $479.35, p<.001$, partial $\eta^{2}=.535$. In all these comparisons the direction of the effect is as expected. That is, in the spatial Stroop $\mathrm{RT}_{\mathrm{I}}$ is significantly higher than $\mathrm{RT}_{\mathrm{C}}$ and, therefore, the $\mathrm{CE}$ appears both when all trials are included $(\mathrm{CE}=$ 
$51 \mathrm{~ms}$ for the total sample) and when pure replicas are eliminated $(\mathrm{CE}=54 \mathrm{~ms}$ for the total sample). The effect size (partial $\left.\eta^{2}\right)$ is larger than .50 in all comparisons. The statistical partial $\eta^{2}$ is interpreted as the proportion of variance of the dependent variable explained by the factor: here, the compatibility of the present trial explains more than $50 \%$ of the variance.

To check if there is SCE in the spatial Stroop the interaction between the two factors (compatibility in trials $\mathrm{N}$ and $\mathrm{N}-1$ ) must be evaluated. The interaction is statistically significant, both when all trials are included and when the pure replicas are eliminated. Specifically, the results with all trials are: first sample, $F(1,377)=711.64, p<.001$, partial $\eta^{2}=$ .654 ; second sample, $F(1,477)=782.48, p<.001$, partial $\eta^{2}=$ .621 ; third sample, $F(1,416)=412.46, p<.001$, partial $\eta^{2}=$ 498. When pure replicas are eliminated the results of the three samples are: first sample, $F(1,377)=259.77, p<.001$, partial $\eta^{2}=.408$; second sample, $F(1,477)=141.99, p<.001$, partial $\eta^{2}=.230$; third sample, $F(1,416)=113.23$, $p<.001$, partial $\eta^{2}=.214$. The effect size is larger for the all trials analysis (.498 to .654) than for the analysis without pure replicas (.214 to .408). That is, the SCE explains a large amount of variance in the RTs even when pure replicas are excluded.

The nature of the interaction is shown in Figure 2: the $\mathrm{CE}$ is smaller when the previous trial is incompatible then when the previous trial is compatible. Specifically, the averages of compatible trials are always smaller than the averages in the incompatible trials. However, the lines are closer together when the previous trials are incompatible when they are compatible.

The SCE decreases when trials with pure replicas are eliminated $(81 \mathrm{~ms}$ with all trials and $50 \mathrm{~ms}$ without the replicas, with the total sample), but the interaction is still significant. This result suggests that the SCE is not due solely to Perceptual Priming. Furthermore the result is robust, since the presence of SCE in the spatial Stroop is replicated in three independent samples.

\section{Verbal Flankers}

Analogous ANOVAs to those in the previous section but with the mean RT obtained with the letters flankers task yielded the following results. The main factor trial $\mathrm{N}$ compatibility is statistically significant when all trials are included in the analysis for the second sample $[F(1,477)=463.28, p<$ .001 , partial $\left.\eta^{2}=.493\right]$ and the third sample $[F(1,416)=$ 966.65, $p<.001$, partial $\left.\eta^{2}=.699\right]$. When pure replicas are eliminated the results are: second sample, $F(1,477)=388.76$, $p<.001$, partial $\eta^{2}=.449$; third sample, $F(1,416)=787.30, p$ $<.001$, partial $\eta^{2}=.654$. In the verbal flankers task, as in the spatial Stroop, the mean $\mathrm{RT}_{\mathrm{I}}$ is significantly higher than the mean $\mathrm{RT}_{\mathrm{C}}$; therefore, the $\mathrm{CE}$ shows up both with all trials (41 $\mathrm{ms}$ for the total sample) and eliminating the pure replicas (40 $\mathrm{ms}$ for the total sample). The observed partial $\eta 2$ statistic value allows concluding that the $\mathrm{CE}$ in this task explains more than $45 \%$ of the variance in the RT of the verbal flankers task.

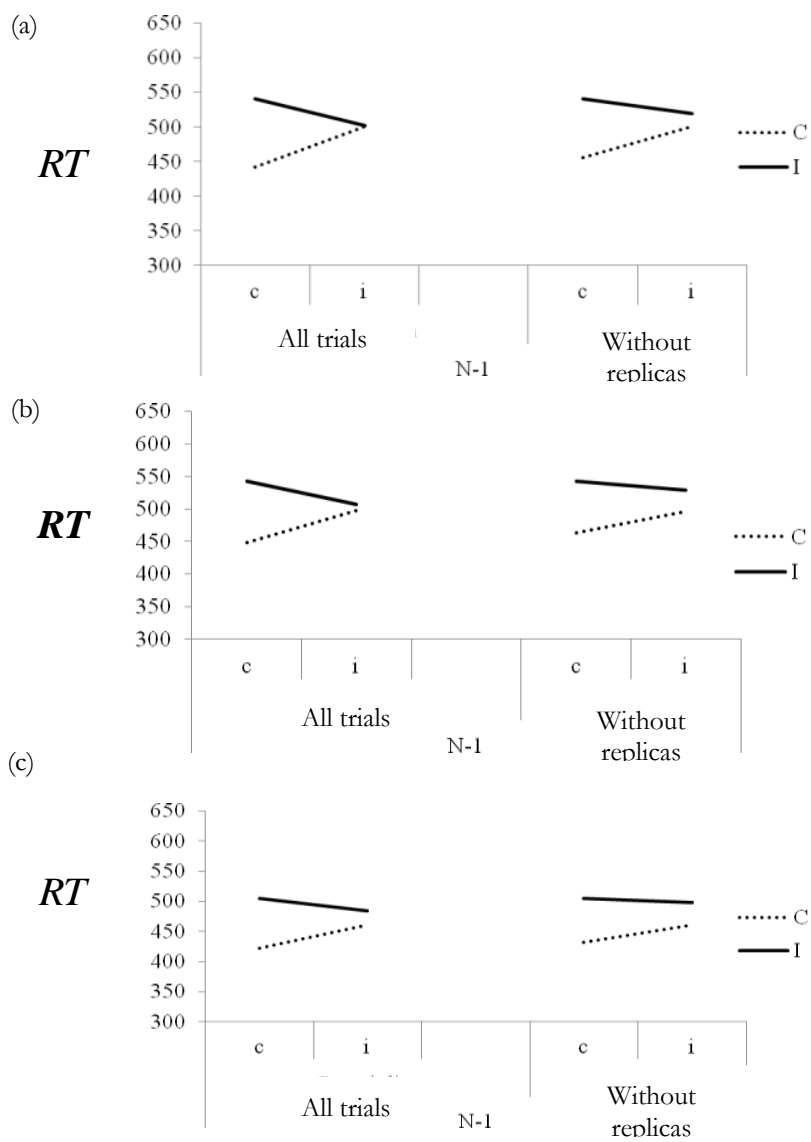

Figure 2. Mean RTs in the spatial Stroop for trials with and without replicas, according to the compatibility of trial $\mathrm{N}$ (compatible or incompatible) and trial N-1 (compatible or incompatible) for the three samples: a, b and c.

Examining the interaction of the two factors (compatibility of trials $\mathrm{N}$ and $\mathrm{N}-1$ ) of the ANOVA for Verbal Flankers allows checking the presence of SCE in this task. The results for the two samples analyzed with all trials indicate a statistically significant interaction for the second sample $\left[F(1,477)=15.96, p<.001\right.$, partial $\left.\eta^{2}=.032\right]$, but not for the third sample $\left[F(1,416)=2.98, p=.085\right.$, partial $\left.\eta^{2}=.007\right]$, although the effect size in the first case is very small. If pure replicas are removed from the analysis, the results are not significant neither for the second sample $[F(1,477)=2.96, p$ $=.086$, partial $\left.\eta^{2}=.006\right]$ nor for the third sample $[F(1,416)=$ $0.08, p=.784$, partial $\left.\eta^{2}<.001\right]$. The absence of a significant interaction in the verbal flankers indicates that the $\mathrm{CE}$ reaches equivalent sizes when the previous trial is compatible or incompatible.

Figure 3 shows that the lines are almost parallel in the two samples, especially when deleting from the analysis the trials that are pure replicas. So, unlike the spatial Stroop, in the verbal flankers task the SCE is not present. 


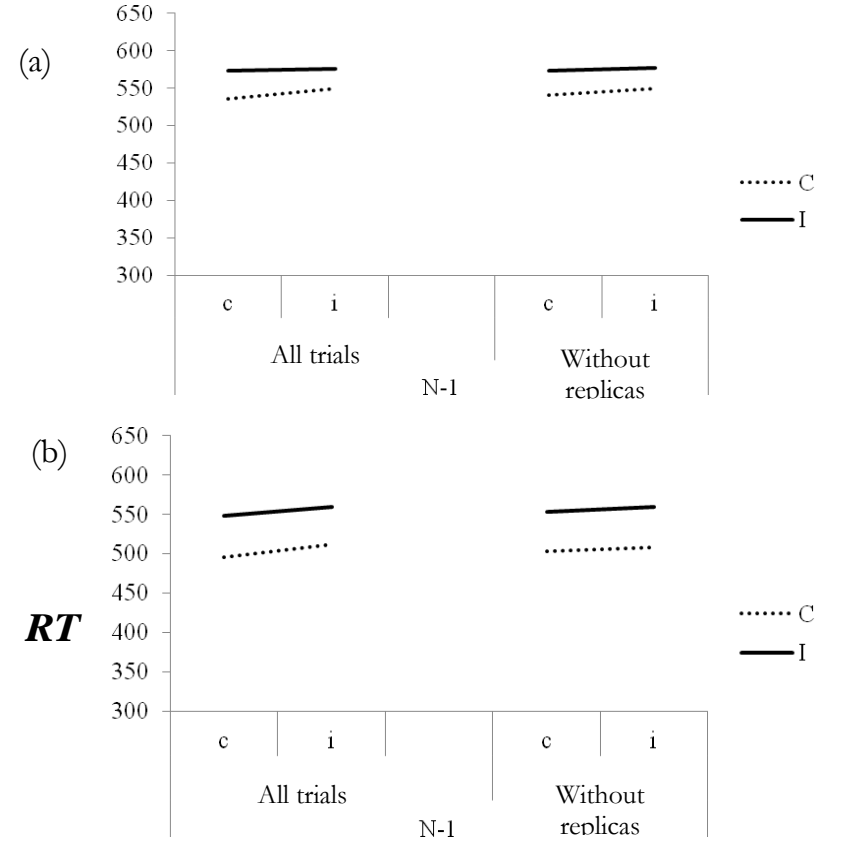

Figure 3. Mean RTs in the verbal task for trials with and without replicas, according to the compatibility of trial $\mathrm{N}$ (compatible or incompatible) and trial N-1 (compatible or incompatible) for the second and third samples.

\section{Numerical Flankers}

ANOVAs analogous to those in the previous sections were applied to each of the three samples. When all trials are included the results are statistically significant in the first sample $\left[F(1,376)=344.38, p<.001\right.$, partial $\left.\eta^{2}=.478\right]$ and in the second sample $\left[F(1,477)=622.75, p<.001\right.$, partial $\eta^{2}=$ .566]. We cannot provide the results of this analysis for the third sample because there were no replicas in this task for this sample. When pure replicas are eliminated the results are: first sample, $F(1,376)=296.59, p<.001$, partial $\eta^{2}=$ .441 ; second sample, $F(1,477)=490.74, p<.001$, partial $\eta^{2}=$ .507 ; third sample, $F(1,416)=432.40, p<.001$, partial $\eta^{2}=$ .510. That is, in the numerical flankers task the mean $\mathrm{RT}_{\mathrm{I}}$ is significantly higher than the mean $\mathrm{RT}_{\mathrm{C}}$ and, therefore, the $\mathrm{CE}$ is present in this task with all trials $(42 \mathrm{~ms}$ for the total sample) and without the pure replicas pure $(39 \mathrm{~ms}$ for the total sample). For the numerical flankers task approximately $50 \%$ of the RT is explained by the compatibility in the present trial.

Again, we checked if the SCE is present in this task assessing the significance of the interaction of the two compatibility factors (trials $\mathrm{N}$ and $\mathrm{N}-1$ ) of the ANOVA. When all trials are included the interaction is statistically significant $\left[F(1,376)=4.51, p=.034\right.$, partial $\left.\eta^{2}=.012\right]$, with a very small effect size; but no significant in the second sample $\left[F(1,477)=3.23, p=.073\right.$, partial $\left.\eta^{2}=.007\right]$. By eliminating the pure replicas from the analysis, in none of the three samples the result is statistically significant: first sample, $F(1,376)=0.73, p=.393$, partial $\eta^{2}=.002$; second sample,
$F(1,477)=3.15, p=.077$, partial $\eta^{2}=.007$; third sample, $F(1,416)=3.70, p=.055$, partial $\eta^{2}=.009$.

As was the case in the verbal flankers task, the absence of interaction indicates that the $\mathrm{CE}$ is equivalent when the previous trial is incompatible as when the previous trial is compatible. Figure 4 shows that the lines are almost parallel in the three samples. Therefore, unlike the spatial Stroop the SCE is not observed in the flankers tasks.

In summary, the results are partially replicated in the three samples and it seems that there are small differences in the $\mathrm{CE}$ among the three tasks. On the average, the CE in spatial Stroop is slightly higher (51-54 $\mathrm{ms}$ in the average, considering the three samples) compared to the CE with flankers tasks (39-42 $\mathrm{ms}$ half as large). In relation to the SCE, the effect is clearly higher in the spatial Stroop than in the flankers tasks, both when all the trials are included as when pure replicas are removed. In contrast, no difference was observed in the SCE between the Verbal and Numerical Flankers tasks.

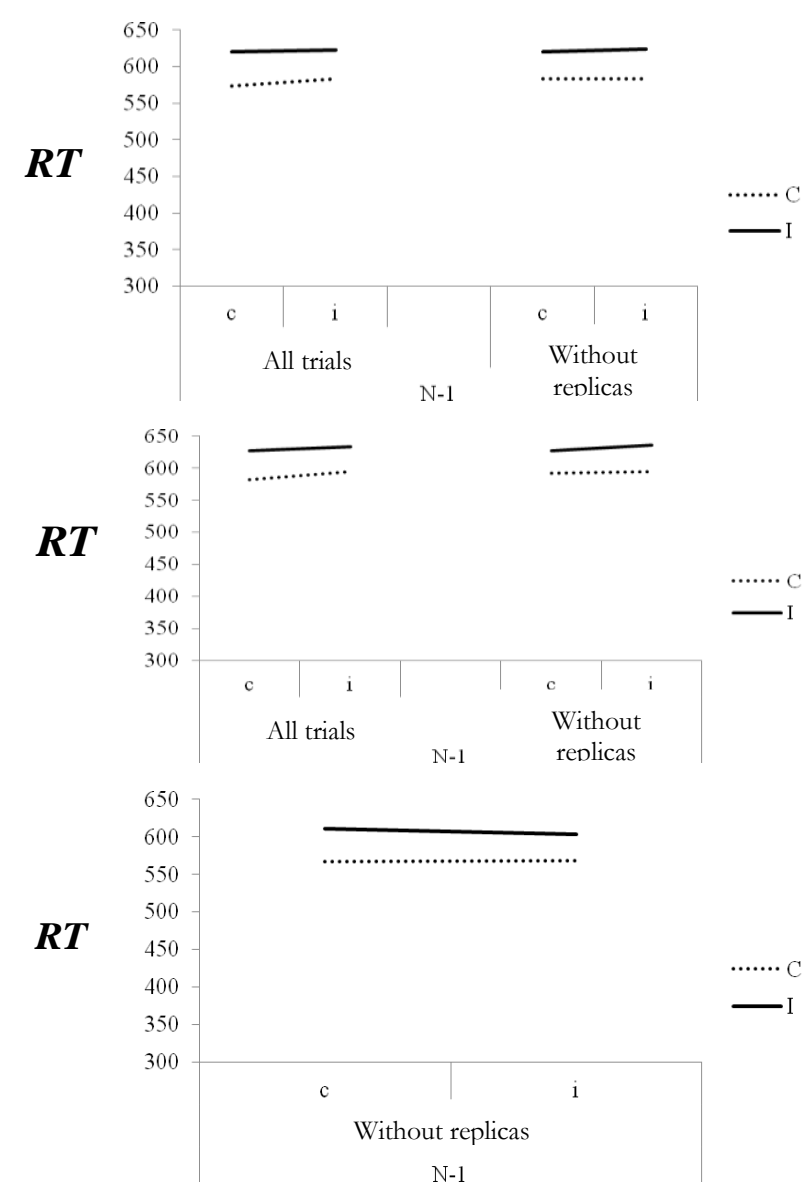

Figure 4. Mean RTs in the numerical flankers task for trials with and without replicas, according to the compatibility of trial $\mathrm{N}$ (compatible or incompatible) and trial N-1 (compatible or incompatible) for the three samples. 


\section{Discussion}

The results found, in three independent samples totaling 1.159 participants, show the presence of CE in the three attentional tasks used, two cognitive tasks of high complexity and one of low complexity. However, significant SCE was observed only in the low cognitive complexity tasks. This general result holds even when the trials that are pure replicas are excluded, which contradicts the perspective of Mayr et al. (2003) and Hommel (1998), but supports Conflict Theory (Botvinick et al., 2001). However, the fact that the SCE does not appear in the more complex tasks contradicts Botvinick et al. (2004) in that the greater complexity should be reflected in a greater presence of cognitive conflict, by increasing top-down control.

The results for the SCE in the spatial Stroop are difficult to explain if one assumes that the only relevant factor is the repetition of the stimulus-response spatial correspondence (Hommel, 1998) or priming of consecutive trials (Mayr et al., 2003). However, the results can be interpreted more easily if it is accepted that is the condition of compatibility of the previous trial (as proposed in the Conflict Theory) the cause of the decrease in the CE when the previous trial was incompatible. Even after eliminating trials with pure replicas (that facilitated the reduction of RT) the SCE still occurs, as other authors found in this type of task (e.g., Wür \& Ansorge, 2005). In addition, remember that our interval between the stimuli and the duration of the stimuli on the screen are closer to those of Mayr et al. (2003) and Hommel (1998) and others have not found SCE when pure replicas are removed from the analysis (Hommel et al., 2004; Nieuwenhuis et al., 2006; Wendt et al., 2006). Therefore, the presence of SCE reinforces the idea that the SCE is due mainly to the presence of conflict (Vergruggen, Notebaert, Liefooghe \& Vandierendock, 2003, Fernández-Duque \& Knight, 2008; Notebaert et al., 2006). However, there is a decrease of the SCE by eliminating pure replicas, which could support, in part, the points of view of Mayr et al. (2003) and Hommel (1998). In the spatial Stroop the SCE can be explained mainly by the presence of cognitive conflict, but repetition contributes to some extent to that effect.

Related to the flankers tasks, the absence of SCE could be interpreted from the Perceptual Priming Theory by the absence of repetition of the same trial consecutively (Mayr et al., 2003). According to this view, the processing would be guided by the stimuli (bottom-up) and by eliminating pure replicas trials the SCE disappears. In the flankers tasks of this study the probability of a repetition of the same stimuli in two consecutive trials was small as compared to those of Mayr et al. (2003), since these authors used four stimuli, whereas in our case we used many more (18 for numerical flankers task and 20 for verbal flankers task). This larger number of stimuli significantly reduced the likelihood of an exact repetition, and therefore, the opportunities of the SCE in flankers tasks are smaller (Gratton et al., 1992; Ullsperger et al., 2005; Verbruggen et al., 2006).
The results of manipulating the cognitive complexity in tasks with conflict (to increase the processing top-down) are against the ideas of Botvinck et al. (2004). Indeed, in more complex tasks (flankers tasks) the SCE was not observed, while in the less complex cognitive (spatial Stroop) there was a clear SCE. One possible explanation may lie in the stimuli used here in the flankers tasks. They usually employ only two or three stimuli, whereas in the present research we used more stimuli, although the aim of including more stimuli was to increase the complexity of the task. Our results are consistent with those of Stümer, Seiss and Leuthold (2005), who found the SCE only in the spatial Stroop and not in the flankers and go/no-go tasks, but these authors did not manipulate top-down the processing in these latest tasks and presented the three types of tasks together alternating spatial Stroop trials with flanker trials or go/no-go trials. Fernandez-Duque and Knight (2008) did manipulate the top-down processing, finding that when this processing was clearly top-down the ESC was observed in their Stroop tasks, but it did not show up when the processing was bottom-up. These results are contrary to the results obtained here, although the way they manipulate the processing was different. They give to the participants a cue about the probability of congruency between the trials. Furthermore, they presented the Stroop tasks in alternating trials.

The finding of SCE in only one of the three tasks is contrary to the idea of a general cognitive mechanism responsible for managing the conflict, as proposed by the Conflict Monitoring Theory (Botvinick et al., 2001). On the contrary, it converges with other approaches that support the idea that the cognitive system handles the conflict specifically according to the task (Kunde \& Wühr, 2006; Wendt et al., 2006). An intermediate position is that of Fernandez-Duque and Knight (2008), who proposed that in the early stages of understanding-habituation the task is more top-down, whereas once the task has been automated the processing is more bottom-up. Our results do not converge with this point of view, because the tasks that need more time for automation should be the most complex cognitive, being precisely those that did not show the SCE, as would be expected if the processing had been top-down.

Another way to test the idea of a general attentional control mechanism has been to observe how the CE modulates between tasks. Both Fernandez-Duque and Knight (2008) as Stümer et al. (2005) alternated different tasks in the trials within a block. The results of both studies show that this provides modulation of a task on the other, that is, the CE of a task depends on the type of trial (compatible or incompatible) from the task of the previous trait. These data have been interpreted as the presence of a nonspecific mechanism of task type, as argued Botvinick et al. (2001). But it would be necessary to perform an experiment in which trials alternate high and low cognitive complexity to check this idea with tasks of the type employed in the present study.

We should also note the possibility that the variability of the results may be associated with the differences between 
the tasks used in the several dozen of published experiments studying the SCE. We believe that both the CE and the SCE are robust enough to hold under small variations in the experimental paradigm. However, it is possible that some of its characteristics interact with manipulations and produce significant differential effects. It remains for future experiments the systematic study of those effects.

In summary, the three tasks used showed the CE, but in the high cognitive complexity tasks the EC was not modulated by the condition of compatibility of the previous trial (compatible or incompatible), as was observed in the lowcomplexity task. None of the theoretical proposals explains fully the results found. The SCE in the spatial Stroop can be explained mainly by the Conflict Monitoring Theory, and to a

\section{References}

Arend, I., Colom, R., Botella, J., Contreras, M. J., Rubio, V., \& Santacreu, J. (2003). Quantifying cognitive complexity: evidence from a reasoning task. Personality and Individual Differences, 35, 659-669.

Baddeley, A. D. (2002). Is working memory still working? European Psychologist, 7, 85-97.

Barriopedro, M. I., \& Botella, J. (1998). New evidence for the zoom model using the RSVP technique. Perception \& Psychophysics, 60(8), 1406-1414.

Bertelson, P. (1961). Sequential redundancy and speed in a serial two-choice responding task. Quarterly Journal of Experimental Psychology, 13, 90-102.

Botella, J. (1997). Los paradigmas de compatibilidad en el estudio de la atención selectiva. Estudios de Psicología, 57, 79-92.

Botella, J. (1998). Atención. In J. Montserrat, La percepción visual, (pp. 499532). Madrid: Biblioteca Nueva.

Botvinick, M. M., Braver, T. S., Barch, D. M., Carter, C. S., \& Cohen J. D. (2001). Conflict monitoring and cognitive control. Psychological Review, 108(3), 624-652.

Botvinick, M. M., Cohen, J. D., \& Carter, C. S. (2004). Conflict monitoring and anterior cingulated cortex: an update. Cognitive Sciences, 8(12), 539546.

Braver, T. S., Cole, M. W., \& Yarkoni, T. (2010). Vive les differences! Individual variation in neural mechanisms of executive control. Current Opinion in Neurobiology, 20, 242-250.

Burle, B., Allain, W., Vidal, F., \& Hasbroucq, T. (2005). Sequential compatibility Effects and cognitive control: Does conflict really matter? Journal of Experimental Psychology: Human Perception and Performance, 31(4), 831-837.

Casey B. J., Thomas, K. M., Welsh, T. F., Badgaiyan, R. D., Eccard, C. H., Jennings, J. R., \& Crone, E. A. (2000). Dissociation of response conflict, attentional selection, and expectancy with functional magnetic resonance imaging. Proceedings of the National Academic of Sciences, 97(15), 8728-8733.

Cohen, J. D. \& Huston, T. A. (1994). Progress in the use of interactive models for understanding attention and performance. En C. Umilta \& M. Moscovitch (Eds.), Attention and performance XV, (pp. 453-456). Cambridge, MA: MIT Press.

Cohen, J. D., Servan-Schreiber, D., \& McClelland, J. L. (1992). A parallel distributed processing approach to automaticity. American Journal of Psychology, 105, 239-269.

Egner, T., \& Hirsch, J. (2005). Cognitive control mechanisms resolve conflict through cortical amplification of task-relevant information. Nature Neuroscience, 8(12), 1784-1790.

Engle, R. W., Kane, M. J., \& Tuholski, S. W. (1999). Individual differences in working memory capacity and what they tell us about controlled attention, general fluid intelligences, and functions of the prefrontal cortex. In A. Miyake \& P. Shah (Eds.), Models of Working Memory: Mechanisms of Active Maintenance and Executive Control (pp. 102-134). Cambridge: Cambridge University Press. lesser extent by Perceptual Priming Theory and Feature Integration Theory. However, the absence of SCE in the two tasks with greater cognitive complexity contradicts the presence of a general mechanism that monitors the conflict, as argued by the Conflict Monitoring Theory. The fact that none of the theories completely accounts the general pattern of results suggests that there may be a factor not explicitly considered in the studies reviewed here: the presence of substantial individual differences when facing tasks of attentional conflict (Braver, Cole \& Yarkoni, 2010). It is possible that different theoretical perspectives are relevant to explain the response patterns of certain individuals but not others? We believe this is a possibility that may be worth exploring in future studies.

Eriksen, B. A., \& Eriksen, C. W. (1974). Effects of noise letters upon the identification of target letters in a non-search task. Perception \& Psychophysics, 16, 143-149.

Eriksen, C. W., \& James, J. D. S. (1986). Visual attention within and around the field of focal attention: A zoom lens model. Perception \& Psychophysics, 40(4), 225-240.

Eriksen, C. W., \& Yeh, Y. Y. (1985). Allocation of attention in the visual field. Journal of Experimental Psychology: Human Perception and Performance, 11(5), 583.

Fernández-Duque, D., \& Knight, M. (2008). Cognitive Control: Dynamic, Sustained, and Voluntary Influences. Journal of Experimental Psychology: Human Perception \& Performance.

Gratton, G., Coles, M. G. H., \& Donchin, E. (1992). Optimizing the use of information: Strategic control of activation of responses. Journal of Experimental Psychology: General, 121(4), 480-506.

Hommel, B. (1998). Event files: Evidence for automatic integration of stimulus-response episodes. Visual Cognition, 5, 183-216.

Hommel, B. (2004). Event files: Feature binding in and across perception and action. Trends in Cognitive Sciences, 8, 494-500.

Hommel, B. (2007). Feature integration across perception and action: event files affect response choise. Psychological Research, 71, 42-63.

Hommel, B., Proctor, R. W., \& Vu, K. P. L. (2004). A feature-integration account of sequential effects in the Simon task. Psychological Research, 68, $1-17$.

Kerns, J. G., Cohen, J. D., MacDonald III, A. W., Cho, R. Y., Stenger, V. A., \& Carter, C. S. (2004). Anterior Cingulate Conflict Monitoring and Adjustments in Control. Science, 303, 1023-1026.

Kunde, W., \& Wühr, P. (2006). Sequential modulations of correspondence effects across spatial dimensions and tasks. Memory \& Cognition, 34(2), 356-367.

Mayr, U., Awh, E., \& Laurey, P. (2003). Conflict adaptation effects in the absence of executive control. Nature Neuroscience, 6(5), 450-452).

McClelland, J. L. \& Rumelhart, D. E. (1981). An interactive activation model of context effects in letter perception: Part I. An account of basic findings. Psychological Review, 88, 375-407.

McDonald III, A. W., Cohen, J. D., Stenger, V. A., \& Carter, C. S. (2000). Dissociating the role of the dorsolateral prefrontal and anterior cingulate cortex in cognitive control. Science, 288(9) June, 1835-1838.

Milham, M. P. \& Banich, M. T. (2005). Anterior Cingulate Cortex: An fMRI Analysis of Conflict Specificity and Functional Differentiation. Human Brain Mapping, 25: 328-335.

Nieuwenhuis, S., Stins, J. F., Posthuma, D., Polderman, T. J. C., Boomsma, D. I., \& de Geus, E. J. (2006). Accounting for sequential trial effects in the flanker task: Conflict adaptation or associative priming? Memory \& Cognition, 34(6), 1260-1272.

Notebaert, W., Gevers, W., Verbruggen, F., \& Liefooghe, B. (2006). Topdown and bottom-up sequential modulations of congruency effects. Psychonomic Bulletin \& Review, 13(1), 112-117. 
Notebaert, W., \& Verguts, T. (2007). Dissociating conflict adaptation from feature integration: A multiple regression approach. Journal of Experimental Psychology: Human Perception and Performance, 33(5), 1256-1260.

Simon, J. R., \& Rudell, A. P. (1967). Auditory S-R compatibility: The effect of an irrelevant cue on information processing. Journal of Applied Psychology, 51, 300-304.

Soetens, E. (1998). Localizing sequential effects in serial choice reaction time with the information reduction procedure. Journal of Experimental Psychology: Human Perception and Performance, 24(2) 547-568.

Soetens, E., Boer, L. C., \& Hueting, J. E. (1983). Expectancy or automatic facilitation? Separating sequential effects in two-choice reaction time. Jounal of Experimental Psychology: Human Perception and Performance, 11(5), 598-616.

Soetens, E., \& Notebaert, W. (2005). Response monitoring and expectancy in random serial RT tasks. Acta Psychologica, 119, 189-216.

Stürmer, B., Seiss, E., \& Leuthold, H. (2005). Executive control in the Simon task: A dual-task examination of response priming and its suppression. European Journal of Cognitive Psychology, 17(5), 590-618.
Ullsperger, M., Bylsma, L. M., \& Botvinick, M. M. (2005). The conflict adaptation effect: It's just priming. Cognitive, Affective \& Behavioral Neuroscience, 5(4), 467-472.

Van Veen, V., Cohen, J. D., Botvinick M. M., Stenger V. A., \& Carter C. S. (2001). Anterior cingulate cortex, conflict monitoring and levels of processing. Neuroimage, 14, 1302-1308.

Verbruggen, F., Notebaert, W., Liefooghe, B., \& Vandierendock, A. (2006). Stimulus and response conflict-induced cognitive control in the flanker task. Psychonomic Bulletin and Review, 13(2), 328-333.

Wendt, M., Kluwe, R. H., \& Peters, A. (2006). Sequential modulations of interference evoked by processing task-irrelevant stimulus features. Journal of Experimental Psychology: Human Perception and Performance, 32(3), 644-667.

Wühr, P., \& Ansorge, U. (2005). Exploring trial-by-trial modulations of the Simon effect. The Quarterly Journal of Experimental Psychology, 58 A(4), 705 731.

(Article received: 21-04-2013; revised: 21-12-2013; accepted: 15-01-2014) 